\title{
Brain metastasis as an isolated late recurrence in small-cell lung cancer
}

\author{
KOICHI KURISHIMA ${ }^{1}$, SHINSUKE HOMMA ${ }^{1}$, KATSUNORI KAGOHASHI ${ }^{2}$, KUNIHIKO MIYAZAKI $^{1}$, \\ MIO KAWAGUCHI ${ }^{1}$, HIROAKI SATOH ${ }^{2}$ and NOBUYUKI HIZAWA ${ }^{1}$ \\ ${ }^{1}$ Division of Respiratory Medicine, Faculty of Medicine, University of Tsukuba, Tsukuba; \\ ${ }^{2}$ Division of Respiratory Medicine, Mito Medical Center, University of Tsukuba, \\ Mito, Ibaraki 10-0015, Japan
}

Received September 16, 2013; Accepted December 11, 2013

DOI: $10.3892 / \mathrm{mco} .2013 .236$

\begin{abstract}
The brain is one of the most common sites of metastasis of small-cell lung cancer (SCLC). In this study, we reported 6 cases with isolated brain relapse of SCLC $\geq 1$ year after the completion of the initial treatment for SCLC. Of the 6 patients, 2 had a solitary brain metastasis and 4 had $\geq 2$ brain metastatic sites. The metastases were identified during a regular check-up computed tomography (CT) scan and were successfully treated. The median interval from the initial diagnosis to the development of brain metastasis was 16 months (range, 13-30 months). All patients received whole-brain irradiation and achieved a complete response. Only one patient developed disturbances of the higher cerebral function. The median interval from whole-brain irradiation to death or last follow-up was 33 months (range, 8-90 months). To the best of our knowledge, these are the first reported cases with isolated brain relapse of SCLC. Although a rare finding, clinicians should be alert on the possibility of such recurrence, particularly in patients who refused prophylactic cranial irradiation.
\end{abstract}

\section{Introduction}

Small-cell lung cancer (SCLC) is characterized by early and widespread metastases, despite good responsiveness to chemotherapy and chemoradiotherapy (1). Overall, $10 \%$ of patients present with brain metastases at the time of initial diagnosis and an additional 40-50\% will eventually develop brain metastases during the course of their disease (1). Brain metastases may be solitary or multiple; however, late isolated brain relapse in SCLC appears to be a rare phenomenon (2). In

Correspondence to: Professor Hiroaki Satoh, Division of Internal Medicine, Mito Medical Center, University of Tsukuba, Miya-machi 3-2-7, Mito, Ibaraki 310-0015, Japan

E-mail: hirosato@md.tsukuba.ac.jp

Key words: isolated brain metastasis, relapse, small-cell lung cancer this study, we report 6 SCLC cases with isolated brain relapse $\geq 1$ year following the completion of the initial treatment for SCLC, which was successfully treated.

\section{Patients and methods}

Patients and staging. The medical records and pathological reports of all patients who were diagnosed with SCLC between January, 2000 and August, 2013 at Divisions of Respiratory Medicine, Faculty of Medicine, Mito Medical Center, University of Tsukuba (Mito, Japan), were reviewed. The data collected included gender, age at diagnosis, smoking history, reason for discovery of lung cancer, histological type, clinical stage, type of treatment and survival following diagnosis. The histological classification was performed according to the World Health Organization (WHO) classification of lung tumors (3). The tumor-node-metastasis staging system was used according to the 7 th edition of the American Joint Committee for Cancer staging system (4). The staging procedure was performed for all the patients using chest computed tomography (CT), brain magnetic resonance imaging (MRI), bone scan, ultrasonograpy and/or CT of the abdomen.

Inclusion criteria. The patients' records were examined in order to assess the inclusion criteria as follows: i) no brain metastasis at the time of initial diagnosis; ii) brain metastasis $\geq 1$ year following the initial diagnosis; and iii) no metastatic sites other than the brain.

This observational study conformed to the Ethics Guidelines for Clinical Studies issued by the Ministry of Health, Labor and Welfare of Japan.

\section{Results}

Patients. During the 14-year period, we identified a total of 6 patients, including 5 males and 1 female, with isolated brain metastasis as a late recurrence in SCLC in our hospitals. All patients were informed on prophylactic brain irradiation and refused treatment. Table I shows clinical characteristics of late brain metastasis as a late recurrence in SCLC patients. The brain metastases were an incidental finding during regular check-up CT scan, without any preceding symptoms. 
Table I. Clinical characteristics of late brain metastasis as a late recurrence in small-cell lung cancer patients.

\begin{tabular}{lcccccc}
\hline $\begin{array}{l}\text { Age } \\
\text { (years) }\end{array}$ & Gender & LD/ED & $\begin{array}{c}\text { Initial } \\
\text { therapy }\end{array}$ & $\begin{array}{c}\text { No. of brain } \\
\text { metastases }\end{array}$ & $\begin{array}{c}\text { Survival from initial } \\
\text { diagnosis (months) }\end{array}$ & $\begin{array}{c}\text { Survival from brain } \\
\text { metastasis (months) }\end{array}$ \\
\hline 76 & F & LD & Chemoradiotherapy & Two & 107 & 90 \\
64 & M & LD & Chemoradiotherapy & Multiple & 38 & 25 \\
74 & M & LD & Chemoradiotherapy & Solitary & 38 & 8 \\
57 & M & LD & Chemoradiotherapy & Multiple & 54 & 41 \\
67 & M & LD & Chemoradiotherapy & Solitary & 52 & 67 \\
63 & M & LD & Chemoradiotherapy & Solitary & 87 & 67 \\
\hline
\end{tabular}

LD/ED, limited disease/extensive disease.

The median age for diagnosis of SCLC was 66 years (range, $57-76$ years).

Treatment and outcome. All patients were administered chemoradiotherapy as the initial treatment and achieved a partial or complete response. The median interval from the initial diagnosis to brain metastasis was 16 months (range, 13-30 months). Of the 6 patients, 2 had brain metastasis and 4 had $\geq 2$ brain metastatic sites. All patients received whole-brain irradiation and achieved a complete response. Only 1 patient developed a disturbance of higher cerebral function almost 5 years after the whole-brain irradiation. The median interval from the brain metastasis to death or last follow-up was 40 months (range, 8-90 months). Overall, two patients survived for $\geq 5$ years. One patient remains alive 38 months after the brain metastasis, whereas the remaining 5 patients eventually succumbed to SCLC.

\section{Discussion}

Late cancer relapse is a growing topic of discussion, as the disease control rates for several types of cancer have increased; therefore, patients with such cancers have a high possibility of prolonged survival. Among various malignancies, the late relapse of SCLC is a well-known but uncommon finding (2,5-7). Among SCLC patients, there have been 7 reported cases of relapse following long-term disease-free survival (8-13). In all those cases, the relapse sites included intrathoracic regions such as the lung, mediastinal lymph nodes, or the pleural cavity. Three of those cases also had brain metastases $(8,10,12)$. Patients with lung adenocacinoma may occasionally develop isolated brain metastasis, but some have a favorable prognosis (5-7). However, late isolated brain relapse of SCLC is a rare finding. In this study, we presented 6 cases of patients with late isolated brain relapse of SCLC, whereas we only identifed 1 other such case (2), who was a long-term SCLC survivor treated with radiation alone and developed a solitary brain metastasis 6.5 years following the initial treatment (2). That patient received radiation therapy and succumbed to the brain metastasis 8.5 years after the initial treatment (2). The autopsy revealed no tumor recurrence at the primary site and no distant metastases except for the brain; the histology of the brain tumor was confirmed as SCLC (2). In our patients, the brain metastases were identified during routine follow-up brain CT scan or MRI, without any preceding symptoms, after a $\geq 1$ year disease free-survival following successful treatment using whole-brain irradiation and additional platinum-containing chemotherapy. In our patients, pathological confirmation of the brain metastases was not obtained; however, as no other disease was evident by systemic imaging evaluation at the time of discovery of the brain lesion and the lesions responded well to whole-brain irradiation and subsequent chemotherapy, they were clinically evaluated as brain metastases from SCLC. In two previous studies on tumors other than lung cancer, 2 cases of patients with isolated brain metastasis as the sole manifestation of a late relapse were reported $(14,15)$. One case was a late isolated intracranial metastasis of liposarcoma in the right lower extremity (14). The relapse was identified 26 years after the initial therapy (14). The other case was an isolated brain metastasis from breast cancer, discovered 9 years after the initial therapy (15). In those 2 cases, additional therapy was unsuccessful in controlling disease progression $(14,15)$. The mechanism underlying such a rare metastasis has not been elucidated. It has been hypothesized that SCLC cells metastasize at a certain time during the clinical course of the disease and they may survive at the metastatic sites, escaping from immune mechanisms and entering a long-term dormancy period, after which time they may start growing again.

Prophylactic cranial irradiation (PCI) is commonly recommended for SCLC, as it was shown to reduce the incidence of brain metastases and significantly improve overall survival in limited- and extensive-disease SCLC in patients who respond to first-line treatment (16). This treatment may increase neuropsychological syndromes and brain abnormalities indicated by CT scans $(17,18)$. However, no significant increase in late sequelae was reported by clinical trials on patients who received PCI $(16,19,20)$. As our patients had limited disease, we explained the indication of PCI at the time of good response to first-time treatment. However, PCI was refused for fear of the appearance of neuropsychological symptoms. Our patients received whole-brain irradiation for isolated brain metastasis at the time of diagnosis of the metastasis. Only 1 patient developed neuropsychological symptoms 5 years after the whole-brain irradiation.

As demonstrated by this study, there may be patients who may expect a long-term survival following additional therapy 
for brain metastasis. However, close follow-up is required to detect metastatic lesions as early as possible, particularly for patients who refused PCI treatment.

\section{References}

1. Quan AL, Videtic GM and Suh JH: Brain metastases in small cell lung cancer. Oncology (Williston Park) 18: 961-972, 2004.

2. Saito Y, Hayakawa K, Mitsuhashi N, et al: Late relapse of small cell lung cancer treated with radiation therapy alone - case report. Lung Cancer 10: 319-324, 1994.

3. Travis WD, Brambilla E, Muller-Hermelink HK and Harris CC (eds): Pathology and Genetics of Tumours of the Lung, Pleura, Thymus and Heart (IARC WHO Classification of Tumours). IARC Press, Lyon, 2004.

4. Edge SB, Byrd DR, Compton CC, et al (eds). Lung AJCC cancer staging manual. 7th edition. Springer, New York, NY pp253-270, 2010.

5. Luketich JD, Martini N, Ginsberg RJ, et al: Successful treatment of solitary extracranial metastases from non-small cell lung cancer. Ann Thorac Surg 60: 1609-1611, 1995.

6. Shahidi $\mathrm{H}$ and Kvale PA: Long-term survival following surgical treatment of solitary brain metastasis in non-small cell lung cancer. Chest 109: 271-276, 1996.

7. Kagohashi K, Satoh H, Yamashita YT and Sekizawa K: Brain metastasis as the first manifestation of lung cancer. Am J Med 114: 420, 2003.

8. Niiranen A: Long-term survival in small cell carcinoma of the lung. Eur J Cancer Clin Oncol 24: 749-752, 1988.

9. Johnson BE, Linnoila RI, Williams JP, et al: Risk of second aerodigestive cancers increases in patients who survive free of small-cell lung cancer for more than 2 years. J Clin Oncol 13 101-111, 1995.

10. Lassen U, Osterlind K, Hansen M, et al: Long-term survival in small-cell lung cancer: posttreatment characteristics in patients surviving 5 to $18+$ years - an analysis of 1714 consecutive patients. J Clin Oncol 13: 1215-1220, 1995.
11. Kitamoto Y, Hayakawa K, Mitsuhashi N, et al: Redevelopment of small cell lung cancer after a long disease-free period: a case report. Jpn J Clin Oncol 32: 30-32, 2002.

12. Al-Ajam M, Seymour A, Mooty M, et al: Ten years of disease-free survival between two diagnoses of small-cell lung cancer: A case report and a literature review. Med Oncol 22: 89-98, 2005.

13. Matsui K, Sawa T, Suzuki H, et al: Relapse of stage I small cell lung cancer ten or more years after the start of treatment. Jpn J Clin Oncol 36: 457-461, 2006.

14. Arepally G, Kenyon LCand and Lavi E: Late onset of isolated central nervous system metastasis of liposarcoma - a case report. Am J Clin Oncol 19: 351-355, 1996.

15. Issa CM, Semrau R, Kath R, et al: Isolated brain metastases as the sole manifestation of a late relapse in breast cancer. J Cancer Res Clin Oncol 128: 61-63, 2002.

16. Blanchard P and Le Péchoux C: Prophylactic cranial irradiation in lung cancer. Curr Opin Oncol 22: 94-101, 2010.

17. Fonseca R, O'Neill BP, Foote RL, et al: Cerebral toxicity in patients treated for small cell carcinoma of the lung. Mayo Clin Proc 74: 461-465, 1999.

18. Welzel T, Niethammer A, Mende U, et al: Diffusion tensor imaging screening of radiation-induced changes in the white matter after prophylactic cranial irradiation of patients with small cell lung cancer: first results of a prospective study. AJNR Am J Neuroradiol 29: 379-383, 2008.

19. Wolfson AH, Bae K, Komaki R, et al: Primary analysis of a phase II randomized trial Radiation Therapy Oncology Group (RTOG) 0212: impact of different total doses and schedules of prophylactic cranial irradiation on chronic neurotoxicity and quality of life for patients with limited-disease small-cell lung cancer. Int J Radiat Oncol Biol Phys 81: 77-84, 2011.

20. Le Péchoux C, Laplanche A, Faivre-Finn C, et al; Prophylactic Cranial Irradiation (PCI) Collaborative Group: Clinical neurological outcome and quality of life among patients with limited small-cell cancer treated with two different doses of prophylactic cranial irradiation in the intergroup phase III trial (PCI99-01, EORTC 22003-08004, RTOG 0212 and IFCT 99-01). Ann Oncol 22: 1154-1163, 2011. 